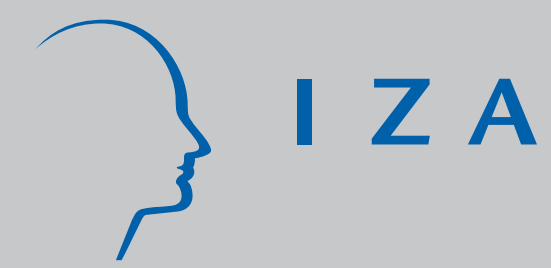

IZA DP No. 801

A Study of the Austrian Labor Market Dynamics Using a Model of Search Equilibrium

Andrey Launov

J une 2003 


\title{
A Study of the Austrian Labor Market Dynamics Using a Model of Search Equilibrium
}

\author{
Andrey Launov \\ University of Munich \\ and IZA Bonn
}

\author{
Discussion Paper No. 801 \\ June 2003
}

\author{
IZA \\ P.O. Box 7240 \\ D-53072 Bonn \\ Germany \\ Tel.: +49-228-3894-0 \\ Fax: +49-228-3894-210 \\ Email: iza@iza.org
}

This Discussion Paper is issued within the framework of IZA's research area Internationalization of Labor Markets. Any opinions expressed here are those of the author(s) and not those of the institute. Research disseminated by IZA may include views on policy, but the institute itself takes no institutional policy positions.

The Institute for the Study of Labor (IZA) in Bonn is a local and virtual international research center and a place of communication between science, politics and business. IZA is an independent, nonprofit limited liability company (Gesellschaft mit beschränkter Haftung) supported by Deutsche Post World Net. The center is associated with the University of Bonn and offers a stimulating research environment through its research networks, research support, and visitors and doctoral programs. IZA engages in (i) original and internationally competitive research in all fields of labor economics, (ii) development of policy concepts, and (iii) dissemination of research results and concepts to the interested public. The current research program deals with (1) mobility and flexibility of labor, (2) internationalization of labor markets, (3) welfare state and labor market, (4) labor markets in transition countries, (5) the future of labor, (6) evaluation of labor market policies and projects and (7) general labor economics.

IZA Discussion Papers often represent preliminary work and are circulated to encourage discussion. Citation of such a paper should account for its provisional character. A revised version may be available on the IZA website (www.iza.org) or directly from the author. 
IZA Discussion Paper No. 801

June 2003

\title{
ABSTRACT
}

\section{A Study of the Austrian Labor Market Dynamics Using a Model of Search Equilibrium*}

In this work we provide a theoretical overview of a search equilibrium model with continuous productivity dispersion and perform its estimation for the Austrian data. We describe empirically the dynamics of market equilibrium outcomes. Special emphasis is made on the analysis of changes in labour mobility and dependence of expected job durations on offered wages. We investigate the influence of excessive labour mobility on the equilibrium profits of firms. Facing a problem of top-coded wage data, we suggest an appropriate adjustment of the existing estimation methodology. Finally, we extend the econometric model for the observed heterogeneity of agents.

JEL Classification: J64

Keywords: search equilibrium, nonparametric estimation, top-coded wages

\author{
Andrey Launov \\ Department of Economics \\ University of Munich \\ Ludwigstr. 28 \\ 80539 Munich \\ Germany \\ Tel.: +49 8921805604 \\ Fax: +498921803954 \\ Email: andrey.launov@Irz.uni-muenchen.de
}

\footnotetext{
* The paper has benefited from comments of a list of people to long to mention by name. My special thanks are to the Institute for Advanced Studies (Vienna) for the given data set and excellent research facilities.
} 


\section{Introduction}

In the present paper we perform a structural estimation of a search equilibrium model with wage posting. We use the results to analyze the changes in equilibrium outcomes, that occurred in the Austrian labor market over the last decade.

Recent advances in the theoretical search equilibrium modelling trigger a wave of applied work. Considerable part of it is connected to estimation of Burdett-Mortensen type of models, where equilibrium wage offer is determined through a solution of a wage-posting game among competing employers. This version is especially suitable to empirical studies, since it endogenously generates continuous theoretical wage offer and earnings distributions. Those can be related to the observed wage and duration data, providing rather simple identification and estimation of the structural parameters of a theoretical model. Among many others working in this area Bowlus et al. (1995), (2001) explore equilibrium wage distributions in the model with heterogeneous producers. Within this framework they study the speed of transition from school to work, and wage differentials of college graduates in the US. Koning et al. (1995) use the model to study structural and frictional unemployment and describe the effects of minimum wage policy experiments in the Netherlands. Ridder and van den Berg (1998) perform a survey of employment and unemployment durations of Dutch employees. Special emphasis deserve contributions of Bontemps et al. (1999), (2000) who develop a simple and powerful nonparametric procedure for the model, where heterogeneity of the demand side is characterized by a continuous productivity distribution.

The goal of the present paper is to provide an empirical description of equilibrium outcomes in the Austrian labor market at two different points of time and see in which direction the changes evolve. In our study we focus mainly on the three indicators of labor market performance. First of all we analyze changes in the expected unemployment durations predicted by the model. The question of interest here is whether the search theoretic framework is capable of grasping the recent big increases in observed unemployment duration. Secondly, we focus on changes in career advancement, job to job transitions and speed of climbing up the earnings ladder. On the job search and dependence of job duration on potential future earnings make the selected theoretical environment especially appropriate for this investigation. This aspect of our study is also important in view of the other empirical surveys of the job mobility in Austria. Mayrhuber and Url (1999), for instance, find that job mobility in the last years became surprisingly high. Thus, in our search equilibrium framework we will try to identify, which factors exactly contribute to the increased employed search activity of the labor supply side. Eventually, we will analyze the changes in profitability of the firms and their monopsony power in wage setting. The question we address here is again risen by Mayrhuber and Url (1999). Recording a considerable increase in labor mobility they ask which effect this can have on equilibrium profits of companies, who may invest in training. Or, addressing this issue from the efficiency wage viewpoint, are the efficiency wages efficient enough to keep workers for sufficiently long time and not loose from early quits. The answer to this question could be given in a search equilibrium framework, where the firms profit is a part of a steady-state solution. Looking into the profit changes over time we will try to give such an answer in this 
paper.

In the present paper we estimate the model with continuous productivity dispersion using the nonparametric methodology of Bontemps et al. (2000). We also consider the issue of the robustness of the model to parametric assumptions on equilibrium offer and productivity distributions.

The paper is organized as follows. The second section provides a brief theoretical overview of the model. The third section describes the data. In the fourth section we describe the estimation methodology. The fifth section presents the results of the work and their discussion. In the conclusion we summarize the main findings.

\section{The Model}

The model incorporates both labor supply side (workers) and labor demand side (employers) who meet on the market. Workers search for jobs and employers offer job opportunities. Both types of agents are rational. Workers maximize their utility of being employed and employers maximize their profits.

Workers utility $U(w)$ is an increasing function of wage ${ }^{1}$ earned. Workers are homogeneous with respect to their opportunity cost of employment $(b)$ and therefore have the same reservation wage $(R)$. There are two states in which workers can be, namely, "employment" and "unemployment", and workers search whenever employed or unemployed. Change of states is assumed to follow Poisson process. Transition from current to a better paid job is also qualified as a change of state, so there are three Poisson arrival rates that govern all transitions in the working history. We define arrival rates of a job offer to unemployed and employed worker as $\lambda_{0}$ and $\lambda_{1}$ respectively. Arrival rate of a layoff is $\delta$. Search process of an individual is formalized as a repeated drawing of job offers from some distribution $F(w)$ and acceptance or rejection of the offer after each draw. It is important to notice that rejected wage offers are unobserved. Available earnings data are just current salaries of employed individuals and so are necessarily accepted wages. Therefore instead of offer distribution $F(w)$ only earnings distribution $G(w)$ can be observed.

Searching workers face an optimal stopping problem. If an agent is unemployed, Mortensen and Neumann (1988) show that the solution for this problem is a reservation wage

$$
R=b+\left(\lambda_{0}-\lambda_{1}\right) \int_{R}^{\bar{w}} \frac{\bar{F}(x)}{\delta+r+\lambda_{1} \bar{F}(x)} d x
$$

where $\bar{F}(x)=1-F(x), \operatorname{supp}(F)=[R, \bar{w}]$ and $r$ is an interest rate. If an agent is employed, the solution is to accept any wage greater than that currently earned. This constitutes workers prescription for utility maximizing behavior. Following Mortensen and Neumann (1988) without loss of generality we can associate $\lambda_{0}$ and $\lambda_{1}$ that satisfy (1) with agents optimal search intensities.

To formulate the employers problem we start with two important findings, both due to Burdett and Mortensen (1998). Let $U$ be a steady state number of unemployed

\footnotetext{
${ }^{1}$ We use the terms "wage", "income" and "earnings" interchangeably. In all cases income before tax is meant.
} 
workers, $M$ - total number of supplying agents and $N$ - steady state number of active firms. Then in equilibrium the probability of encountering an unemployed agent is $U / M=\delta\left(\delta+\lambda_{0}\right)^{-1}$. Moreover, in equilibrium there exists an unambiguous dependence between unobserved offer and observed earnings distribution $(F, G)$ and density $(f, g)$ functions

$$
\bar{F}(w)=\frac{\delta[1-G(w)]}{\delta+\lambda_{1} G(w)} \quad f(w)=\frac{\delta\left(\delta+\lambda_{1}\right)}{\left[\delta+\lambda_{1} G(w)\right]^{2}} g(w)
$$

These identities make possible to derive the amount of workers $l$ attracted in the steady state by any offered wage $w$

$$
l(w)=\frac{M-U}{N} \frac{\delta\left(\delta+\lambda_{1}\right)}{\left[\delta+\lambda_{1} \bar{F}(w)\right]^{2}}=\frac{M-U}{N} \frac{\left[\delta+\lambda_{1} G(w)\right]^{2}}{\delta\left(\delta+\lambda_{1}\right)}
$$

$l(w)$ already depends on the unknown search intensity parameters. Employers now face a problem of maximizing their profit with respect to wage paid

$$
\pi=\max _{w}(p-w) l(w)
$$

with $l$ given by (3). In the considered version of the model employers are heterogeneous with respect to their productivity. The probability distribution of productivity across active firms $\Gamma(p)$, is assumed to be continuous, $\sup p(\Gamma)=[\underline{p}, \bar{p}]$. Bontemps et al. (2000) show that under continuity assumption there exists a unique single valued, monotone and continuous function $w=K(p)$, which maps the support of the productivity distribution into the support of the wage offer distribution. This implies that each $p$-type firm offers only one wage, which rules out discontinuity of the wage offer distribution, immanent to the models with discrete productivity dispersion. Existence and uniqueness of $K(p)$ allows expressing first order conditions for firms in terms of firms productivity. Indeed, taking the derivative of (4) with respect to $w$, and using some algebra single firm optimality conditions become

$$
p=w+\frac{\delta+\lambda_{1} \bar{F}(w)}{2 \lambda_{1} f(w)}=w+\frac{\delta+\lambda_{1} G(w)}{2 \lambda_{1} g(w)}
$$

where $p$ is a known firm-specific constant. Bontemps et al. (2000) show that using FOC in (5) one can derive the probability density of the productivity levels of firms, operational in equilibrium

$$
\begin{aligned}
\gamma(p) & =\frac{2 \lambda_{1} f(w)^{3}}{\lambda_{1} f(w)^{2}-f^{\prime}(w)\left[\delta+\lambda_{1} \bar{F}(w)\right]} \\
& =\frac{2 \delta \lambda_{1}\left(\delta+\lambda_{1}\right) g(w)^{3}}{3 \lambda_{1} g(w)^{2}\left[\delta+\lambda_{1} G(w)\right]^{2}-g^{\prime}(w)\left[\delta+\lambda_{1} G(w)\right]^{3}}
\end{aligned}
$$

Moreover, they use equation (5) to find an optimal wage offer of a firm with given productivity level $p$, i.e. find $K(p)$. Provided that in equilibrium $F(w)=\Gamma(p)$ a solution for the optimal equilibrium wage offer is:

$$
w_{\text {opt }}=K(p)=p-\left[\delta+\lambda_{1} \bar{\Gamma}(p)\right]^{2} \int_{R}^{p} \frac{d x}{\left[\delta+\lambda_{1} \bar{\Gamma}(x)\right]^{2}}
$$


Bontemps et al. (2000) show that whenever an upper bound of the support of the wage offer density is finite there exists at least one equilibrium on the market. A formal definition of market equilibrium concludes the theoretical overview.

Definition 1 A market search equilibrium is a triple $\left\{F(w), \mathcal{W}, \mathcal{K}_{p}\right\}$ such that:

1) The distribution of wage offers is $F(w)=\int F(w \mid p) d \Gamma(p)$, where $\Gamma(p)$ is a productivity distribution of firms, active in the market

2) $\mathcal{W}=\max \left\{R, w_{\text {current }}\right\}$ is the workers best response to firms wage-posting behavior; $R$ defined in (1)

3) $\mathcal{K}_{p}=\arg \max \{\pi(p, w) \mid R \leq w \leq \bar{w}\}$ is a set of profit-maximizing wages posted in equilibrium by each $p$-type firm; $\pi(p, w)$ defined in (4) and $\mathcal{K}_{p}$ defined in (7)

Burdett and Mortensen (1998) show that for any $p$-type firm the unique offer distribution $F(w \mid p)$ that satisfies Definition 1 is given by

$$
F(w \mid p)=\frac{1+\kappa_{1}}{\kappa_{1}}\left[1-\sqrt{\frac{p-w}{p-w_{\min }}}\right]
$$

Theoretical description above represents the equilibrium solution exclusively in terms of structural parameters and employers productivity. In the most straightforward case, researcher may use productivity data and, assuming some parametric form for $\Gamma(p)$, construct the likelihood function. In case only wage data are available, some more elaboration will be required to compute the equilibrium wage offer distribution. Namely, for its calculation one will need to know $p$ in order to get (8). This will involve solving for the inverse of $(7)$, which is a tedious task. Therefore in such situation it is more efficient to follow the nonparametric estimation procedure suggested by Bontemps et al. (2000). This is what we do in the present work.

\section{The Data}

In the present survey we use data from the Austrian Social Security Records. They represent working history of individuals who were followed through a fifteen year period from 1984 to 1998. All observations are made on 30.05 of each year. Individual data include gender, age, income, professional affiliation, employment status and various indicators on employment/unemployment durations. Using the guidelines of Ridder and van den Berg (1998) we draw two samples at 1988 and 1994 and restore labor market histories of all sampled individuals. All individuals are divided into the four employment status categories, namely "employed", "unemployed", "on study" and "other". In what follows we consider only "employed" and "unemployed" ones. The reason is that the theoretical model is restricted to only these two states of the labor market. It is believed that individuals who fall into the rest of two groups have incentives different from the agents described by the model. Therefore they should be left out.

For the same reason we exclude from our sample part-time workers. Unfortunately, there is no direct indication of part-time employment in the data. To draw samples with the least possible noise we argue that if an agent works on a full-time 
Table 1 "Duration Data for the Austrian Labor Market (months, individuals)"

\begin{tabular}{|c|c|c|}
\hline & 31.05 .1988 & 31.05 .1994 \\
\hline Number of Individuals & 3404 & 3726 \\
\hline I. EMPLOYED & 3110 & 3361 \\
\hline \multicolumn{3}{|l|}{ Transitions } \\
\hline 1) - to job & 1011 & 731 \\
\hline 2) - to unemployment & 757 & 707 \\
\hline 3) - other & 616 & 362 \\
\hline \multicolumn{3}{|l|}{ Durations } \\
\hline \multicolumn{3}{|l|}{$\overline{\text { Uncensored }}$} \\
\hline - mean & 43.189 & 42.324 \\
\hline - standard deviation & 34.884 & 33.008 \\
\hline - number of observations & 1146 & 1288 \\
\hline \multicolumn{3}{|l|}{ Censored } \\
\hline - left & 622 & 150 \\
\hline 4) - right & 257 & 1085 \\
\hline 5) - both left and right & 469 & 476 \\
\hline Censored Durations Total: & 1348 & 1711 \\
\hline II. UNEMPLOYED & 294 & 365 \\
\hline \multicolumn{3}{|l|}{ Transitions } \\
\hline 6) - to job & 34 & 29 \\
\hline 7) - other & 257 & 288 \\
\hline \multicolumn{3}{|l|}{ Durations } \\
\hline \multicolumn{3}{|l|}{ Uncensored } \\
\hline - mean & 6.123 & 5.638 \\
\hline - standard deviation & 8.358 & 3.226 \\
\hline - number of observations & 34 & 29 \\
\hline \multicolumn{3}{|l|}{ Censored } \\
\hline - left & - & - \\
\hline 8) - right & 3 & 48 \\
\hline 9) - both left and right & - & - \\
\hline Censored Durations Total: & 3 & 48 \\
\hline
\end{tabular}

\section{COMMENTS:}

a) The number of employed individuals I. is a sum from 1) to 5), i.e. the sum of completed, left-, right- and both left and right censored durations.

b) Left censored durations are fully absorbed by the sum from 1) to 3), i.e. the sum of right-observed durations.

c) The number of unemployed individuals II. is a sum from 6) to 9), i.e. again the sum of completed, left-, right- and both left and right censored durations.

d) Total number of individuals is a sum of I. and II. 
basis, her income is at least as high as the legal minimum wage before tax. Thus people, with income below the minimum are left out of consideration. Here we should also notice that in fact there is no uniform legal minimum wage in Austria. Instead, every year unions in all industries bargain with employers for minimum wages that should be paid in respective industries throughout the whole year. As an approximation for a single minimum wage we take an average of agreed within-industry wages, which are available from the annual reports of the Austrian Central Statistical Office.

The described processing results in two wage and duration data samples with 3404 (294) employed (unemployed) at 30.05.88 and 3726 (365) employed (unemployed) at 30.05.94. Summary statistics of the duration lengths is given in Table 1 .

There are two problems with the resulting samples. The first one is a so called "length-biasedness" of duration data, which is connected with our way of sampling the durations. The problem is such that the spells with the longer length have in general higher probability to be included into the sample. To overcome this problem we construct the likelihood on the basis of the joint distribution of elapsed and residual durations as suggested by Ridder (1984). The treatment of length-biasedness is described in details in Section 4.1. The second problem is that the wages in the original data set are top-coded. Right censoring amounts to about $10 \%$ in both samples. This makes direct application of the nonparametric estimation procedure of Bontemps et al. (2000) problematic. Our proposed solution to this problem is presented in Section 4.2 .

\section{Estimation Methodology}

Structural parameters $\left\{\lambda_{0}, \lambda_{1}, \delta\right\}$ are estimated from the econometric model built on wage and duration data. General approach to the construction of the likelihood is based on Lancaster (1990) and Ridder and van den Berg (1998). Additionally we discuss modifications, which are necessary to account for the particularities of our data.

\subsection{The Likelihood}

The backbone process of the model is Poisson, so waiting time between any two adjacent events is exponentially distributed with parameter $\theta$. Though, due to the non-randomness of the sample this property can not be applied directly. Instead we follow Ridder (1984) and analyze a joint distribution of elapsed $\left(t_{e}\right)$ and residual $\left(t_{r}\right)$ durations of a spell. On the distribution of the elapsed duration it is known that certain time $t_{e}$ ago there was a renewal of states and since then an individual spent at least $t_{e}$ in a new state. Renewal probability for $\operatorname{Poi}(\theta)$ is shown to be equal to $\theta$. On the distribution of the residual duration our knowledge is that given a certain elapsed time $t_{e}$ an individual spends in this state additional time $t_{r}\left(t_{r}>0\right)$. Therefore appropriate densities are:

$$
\begin{array}{ll}
\text { Elapsed: } & f\left(t_{e}\right)=\theta e^{-\theta t_{e}} \\
\text { Residual: } & f\left(t_{r} \mid t_{e}\right)=\theta e^{-\theta t_{r}}, t_{r}>0 \\
\text { Joint: } & f\left(t_{e}, t_{r}\right)=\theta^{2} e^{-\theta\left(t_{e}+t_{r}\right)}, t_{r}>0
\end{array}
$$


Hazard of $\operatorname{Exp}(\theta)$ is $\theta$, so for unemployed individuals hazard of exit from current state is just the arrival rate of job offer i.e. $\theta=\lambda_{0}$. For employed individuals hazard of exit from current job is a sum of the transition intensity to a job, which pays higher wage (i.e. arrival of acceptable job offer), and the transition intensity to unemployment. So: $\theta=\lambda_{1} \bar{F}(w)+\delta$.

To formulate likelihood contributions of unemployed $\left(\mathcal{L}_{u n}\right)$ and employed $\left(\mathcal{L}_{\text {empl }}\right)$ individuals we also notice that the probability of encountering unemployed agent in equilibrium is $\delta\left(\delta+\lambda_{0}\right)^{-1}$. Then the probability of meeting an employed individual who works at the observed wage is $\lambda_{0} g(w)\left(\delta+\lambda_{0}\right)^{-1}$. Additionally, to account for multiple destinations in the cases of transition from job to job and from job to unemployment the likelihood contribution of employed individual should be multiplied with the transition probabilities:

$$
\pi_{j \rightarrow u}=\frac{\delta}{\delta+\lambda_{1} \bar{F}(w)} \quad \text { and } \quad \pi_{j \rightarrow j}=\frac{\lambda_{1} \bar{F}(w)}{\delta+\lambda_{1} \bar{F}(w)}
$$

To account for censored durations, in case of left censoring we drop the renewal probability and in case of right censoring we change residual density by its survivor. With these results $\mathcal{L}_{\text {un }}$ and $\mathcal{L}_{\text {empl }}$ individuals become:

$$
\begin{gathered}
\mathcal{L}_{u n}=\frac{\delta}{\delta+\lambda_{0}} \lambda_{0}^{2-d_{r}-d_{l}} \exp \left\{-\lambda_{0}\left(t_{e}+t_{r}\right)\right\} f(w)^{1-d_{r}} \\
\mathcal{L}_{\text {empl }}=\frac{\lambda_{0} g(w)}{\delta+\lambda_{0}}\left[\delta+\lambda_{1} \bar{F}(w)\right]^{1-d_{l}} \exp \left\{-\left[\delta+\lambda_{1} \bar{F}(w)\right]\left(t_{e}+t_{r}\right)\right\}\left[\left[\lambda_{1} \bar{F}(w)\right]^{d_{t}} \delta^{1-d_{t}}\right]^{1-d_{r}}
\end{gathered}
$$

Here $d_{l}=1$, if a spell is left-censored, 0 otherwise; $d_{r}=1$, if a spell is right-censored, 0 otherwise; $d_{t}=1$ if there is a job-to-job transition, 0 otherwise.

Using steady state identity for distributions (2), we substitute unknown wage offer distribution $(F)$ and density $(f)$ with expressions containing earnings distribution $(G)$ and density $(g)$. Such substitution enables us using a suggested by Bontemps et al. (2000) "nonparametric 3-step procedure" of structural parameters estimation. On its first step we compute non-parametric estimates of $g(w)$ and $G(w)$. On the second step we substitute values of $g(w)$ and $G(w)$ in the likelihood function with their estimates from the step one and maximize the likelihood with respect to $\lambda_{0}, \lambda_{1}$ and $\delta$. On the third step equilibrium outcomes $(4)-(7)$ derived from the theory are evaluated using estimates from the steps one and two.

As already mentioned in Section 2, application of this estimation procedure simplifies calculations greatly. Moreover, Bontemps et al. (2000) argue that nonparametric procedure gives the highest possible fit to the observed data. In our analysis we can actually test this claim, comparing the estimated equilibrium wage offer distributions with their assumed parametric counterparts. We return to this issue in Section 5.3.

Finally we comment on the estimation of the support bounds of earnings distribution. Bowlus et al. (1995) suggest that $R=\min (w)$ and $\bar{w}=\max (w)$. In the present paper we rather use average of agreed within-industry minimum wages as an estimator for $R$. For $\bar{w}$ we keep $\bar{w}=\max (w)$. Following Bowlus et al. (1995), application of $\max (w)$ leads to non-normality of MLE of parameters of interest. Therefore we bootstrap standard errors. 


\subsection{Nonparametric Features of the Likelihood and the Prob- lem of Top-Coded Wages}

It would be straightforward to estimate the model now if there were no additional complication connected with the data. As mentioned in Section 3, about $10 \%$ of top earnings observations are censored. Absence of information on the wages from the upper decile of earnings distribution makes non-parametric estimation of its right tail unfeasible. To solve this problem we suggest to approximate the tail by some known distribution. Fortunately, properties of earnings distribution allow doing so. As Fichtenbaum and Shahidi (1988) suggest, common practice would be to approximate it by the right tail of Pareto distribution. So we will informally split the support of $G(w)$ in two intervals: on the first interval we use nonparametric estimates of $g(w)$ and $G(w)$, on the second one $g(w)$ and $G(w)$ are to be of a Pareto form.

Consider the first interval. With presence of right censoring in the observed income natural nonparametric estimator of earnings distribution is a Product-Limit Estimator. To estimate the density we follow Padgett (1988), who suggests a version of a Blume-Susarla estimator suited to the case when right censoring is not random and the censoring threshold is the same constant. Formally:

$$
\tilde{g}(w)=\left[n h^{-1}\right] \sum_{j=1}^{n} K\left(\frac{w-W_{j}}{h}\right)\left[I_{j}=1\right]
$$

where $I_{j}$ is an indicator function, which takes value 1 if $w_{j}$ is less then the value of the censoring threshold and zero otherwise. Padgett (1988) justifies an application of Gaussian kernel for (12). Additionally, Vuong et al. (2000) show that whenever the distribution has a compact set as a support any kernel density estimator is asymptotically downward biased towards tails. Bontemps et al. (2000) state that this bias is precisely $E[\hat{g}(w)] \rightarrow \frac{g(w)}{2}$ and suggest the following bias-corrected kernel estimator:

$$
\hat{g}(w)=\tilde{g}(w)\left[\Phi\left(\frac{x-\underline{w}}{h}\right)\right]^{-1}
$$

In view of right censoring and subsequent Pareto approximation (12) presents a version of the estimator with only left tail correction making it suitable for our study.

Now consider the approximation of earnings distribution on the second interval. The length of this interval is determined by $\log -\log$ plot of $1-\hat{G}(w)$. By the property of Pareto distribution the approximation is justified only on the segment where $\ln (1-$ $\hat{G}(w))$ is linear against $\ln (w)$. In our study linearity of $\ln (1-\hat{G}(w))$ amounts to top $20 \%$ of wages in both samples. By substitution of $\ln (1-\hat{G}(w)$ into the equation linear in $\ln (w)$ both scale and shape parameters of Pareto distribution are estimated by NLS.

With knowledge of the exact form of Pareto approximate we specify likelihood contributions of individuals with top-coded earnings in a standard way. If the wage is top-coded the individual contribution to the likelihood is $P\left(W \geq w^{c e n s}, t_{e}, t_{r}\right)$. If, however, the wage is observed but still falls in the second interval, the likelihood contribution is the same as (10) with the only difference that now Pareto pdf and cdf 
will be substituting $g(w)$ and $G(w)$. This implies that contribution of all employed workers to the likelihood is ${ }^{2}$

$$
\begin{aligned}
\mathcal{L}_{\text {empl }}= & {\left[\prod_{\{A\}} \mathcal{L}_{\text {empli }}\left(\xi \mid t_{e_{i}}, t_{r_{i}}, g\left(w_{i}\right), G\left(w_{i}\right)\right)\right] \times\left[\prod_{\{B\}} \mathcal{L}_{\text {empli }}\left(\xi \mid w_{i}, t_{e_{i}}, t_{r_{i}}\right)\right] } \\
& \times\left[\prod_{\{C\}}\left[\int_{w^{\text {cens }}}^{\bar{w}} f\left(\xi \mid w_{i}, t_{e_{i}}, t_{r_{i}}\right) d w\right] \pi_{i}\right]
\end{aligned}
$$

where $\{A\}$ is the set of individuals for who earnings density and distribution were calculated nonparametrically (about $80 \%$ of all employed), $\{B\} \cup\{C\}$ is the set of individuals for who Pareto approximation of earnings distribution was applied (approximately $20 \%$ all employed). Within $\{B\} \cup\{C\}$ subset $\{B\}$ contains individuals with observed wages $(\approx 10 \%$ of all) and subset $\{C\}$ contains individuals with topcoded wages $\left(\approx 10 \%\right.$ of all). In the last square bracket $\pi_{i}$ represents an appropriate probability term, discussed in Section 4.1.

Contribution of all unemployed agents to the likelihood is

$$
\mathcal{L}_{u n}=\prod_{\{U\}} \mathcal{L}_{u n_{i}}\left(\xi \mid t_{e_{i}}, t_{r_{i}}\right)
$$

As there were no instances of transition from unemployment to a job with top-coded wage in this particular study, (14) does not take an account for that. Otherwise its construction would have been the same as in (13).

\subsection{The Likelihood and Observed Heterogeneity}

Knowledge of estimated parameters is already sufficient to describe labor market equilibrium empirically. Though, having a single parameter $\left\{\lambda_{0}, \lambda_{1}, \delta\right\}$ to approximate the whole set of individual-specific parameters $\left\{\left\{\lambda_{0_{i}}\right\},\left\{\lambda_{1_{i}}\right\},\left\{\delta_{i}\right\}\right\}, i=1, \ldots n$, may be too restrictive, because even observed heterogeneity of employees is neglected. Theoretical model assumes that all the workers are homogeneous with respect to opportunity cost of employment. However, they may be different with respect to gender, age, skills etc. Therefore, to make more precise inference we suggest to extend an econometric specification and allow for observed heterogeneity. To do so we borrow from the idea of Ridder, van den Berg (1998) and treat the observed qualities as covariates. Structural parameters of the model then could be specified as follows

$$
\lambda_{0}=\exp \left(X \beta_{1}\right), \quad \lambda_{1}=\exp \left(X \beta_{2}\right), \quad \delta=\exp \left(X \beta_{3}\right)
$$

In the present work we study variation of structural parameters induced by age and gender. Thus, $X$ consists of the constant, age and gender variables. Notice that if $X$ contains the constant only, the whole specification reduces to the basic model, described in Section 4.2-3. In practice we estimate the basic model as a special case of the extended one. The results of homogeneous model estimation and estimation in presence of covariates are reported in Section 5.1 and 5.2 respectively.

\footnotetext{
${ }^{2}$ For convenience of notation here $\xi \equiv\left\{\lambda_{0}, \lambda_{1}, \delta\right\}$.
} 


\section{Estimation Results and Discussion}

The model is estimated for data collected at two different time points -31.05 .88$ and 31.05.94. This allows comparing equilibrium outcomes and on their evolution. In what follows we report the transformed estimation results, which are more suitable for economic interpretation. Immediate results are presented in Table A1 of the Appendix.

\subsection{Estimation Results - The Model with Homogeneous Work- ers}

In Table 2 we report the reciprocals of estimated parameters of the model with homogeneous workers. We start our interpretation from unemployment durations. Following Mortensen and Neumann (1988) mean employment duration is just a reciprocal hazard of exit from unemployment $\lambda_{0}^{-1}$. From Table 2 we see that the expected length of unemployment significantly increased from 5.5 to 12 months. This fact may have two possible explanations. On one hand it may become preferable to stay longer in unemployment due to an increased generosity of a benefit system. On the other, however, it may become more difficult to find a job due to an increased competition on the market or cyclicity. According to Winter-Ebmer (1998), even very big increases of benefit duration in Austria are not able to cause proportional (and sometimes even significant) increase in unemployment duration. Furthermore, if we take the ratio of unemployed to employed individuals as an indicator of market activity, we can see that these make 0.103 and 0.098 for 1988 and 1994 respectively. This does not indicate a slowdown of economy in the second period if compared to the first one. Therefore we may conclude that over the last decade the Austrian labor market became more demanding to a quality of workers.

Table 2 "Estimated Frictional Parameters"

\begin{tabular}{|c|c|c|}
\hline & Sample 1988 & Sample 1994 \\
\hline $1 / \lambda_{0}$ & $\begin{array}{c}5.47210(0.36245) \\
{[4.968,5.951]}\end{array}$ & $\begin{array}{c}12.28694(0.27535) \\
{[11.660,12.824]}\end{array}$ \\
\hline $1 / \lambda_{1}$ & $\begin{array}{c}33.19244(1.60169) \\
{[29.801,36.682]}\end{array}$ & 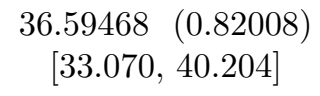 \\
\hline $1 / \delta$ & $\begin{array}{c}130.75113(3.09881) \\
{[127.657,133.752]}\end{array}$ & $\begin{array}{c}119.59049 \\
{[116.890,122.211]}\end{array}$ \\
\hline $\log ($ Likelihood) & -37246.69 & -45091.92 \\
\hline
\end{tabular}

(standard errors of parameters in parenthesis; bootstrap 95\% confidence intervals based on 1000 replications in square brackets) 
Inference about expected employment durations predicted by the model is less straightforward. By the same argument of Mortensen and Neumann (1988) expected job duration is equal to the reciprocal hazard of exit to a better job $\left[\lambda_{1} \bar{F}(w)\right]^{-1}$. So, its calculation now presumes a knowledge of wage offer distribution. Even though it is possible to estimate offer distribution in this setting (see Figures 1-2 of the Appendix), all inference in the existing literature was so far based only on the reciprocal employed search intensity $\lambda_{1}^{-1}$. In the present paper we rather try to consider $\left[\lambda_{1} \bar{F}\left(w_{i}\right)\right]^{-1}$ and link job duration with possible wage offer. This extension should give more comprehensive description of the expected duration of employment. To make the estimated expected durations comparable across time we evaluate $\bar{F}\left(w_{i}\right)$ at the wages, which are the averages of respective wage deciles of the earnings distribution. Table 3 presents the lengths of expected job durations (in months) of an agent, who earns average income of each and every decile. Visual presentation of these results is given in Figure 3 of the Appendix.

Table 3 "Estimated Expected Job Durations At Given Income (months)"

\begin{tabular}{|c|c|c|}
\hline $\begin{array}{c}\text { Average Earnings } \\
\text { Over Deciles of Earnings } \\
\text { Distribution }\end{array}$ & $\begin{array}{c}\text { Expected Job } \\
\text { Duration (1988) }\end{array}$ & $\begin{array}{c}\text { Expected Job } \\
\text { Duration (1994) }\end{array}$ \\
\hline 1 & 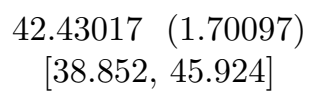 & $\begin{array}{c}44.34061 \quad(1.85277) \\
{[40.599,47.971]}\end{array}$ \\
\hline 2 & $\begin{array}{c}64.72474 \quad(2.00067) \\
{[60.816,68.505]}\end{array}$ & 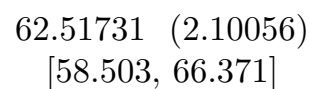 \\
\hline 3 & $\begin{array}{c}93.90406 \quad(2.47684) \\
{[89.605,98.098]}\end{array}$ & 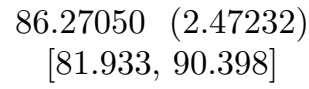 \\
\hline 4 & 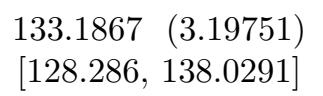 & $\begin{array}{c}116.1938 \\
{[111.404,120.68851)}\end{array}$ \\
\hline 5 & $\begin{array}{cc}186.7297 & (4.24806) \\
{[180.952,} & 192.634]\end{array}$ & $\begin{array}{c}155.8619 \\
{[150.405,} \\
{[3.7191 .018]}\end{array}$ \\
\hline 6 & $\begin{array}{c}266.2852(5.87089) \\
{[259.004,273.759]}\end{array}$ & 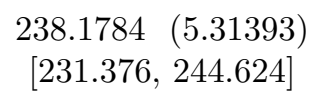 \\
\hline 7 & $\begin{array}{c}395.2196 \quad(8.55978) \\
{[385.520,405.617]}\end{array}$ & $\begin{array}{cc}337.0235 & (7.28666) \\
{[328.266,} & 345.112]\end{array}$ \\
\hline
\end{tabular}


8

9

10
$648.1672 \quad(13.9034)$

[633.532, 663.735]

$1335.316 \Leftrightarrow \infty$

(28.47675)

$3769.770 \Leftrightarrow \infty$

(80.25259)
$511.3346 \quad(10.8200)$

[499.527, 522.5928]

$919.9729 \Leftrightarrow \infty$

(19.15996)

$1967.350 \Leftrightarrow \infty$

(40.63293)

(standard errors of parameters in parenthesis, bootstrap 95\% confidence intervals base on 1000 replications in square brackets)

Firstly we notice that expected job duration of agents, whose earnings belong to upper two deciles, exceeds potential job tenure (more than 60 years). This result is quite natural, though. It just tells that people, who earn very high income practically loose an incentive to search for a better job and are happy to stay on the current job forever. Of bigger interest are the results for the rest of the workers. From both Table 3 and Figure 3 we readily obtain the verification of the reduction in mean job durations over the last decade. Thus we match the fact reported earlier by Url and Mayrhuber (1999). In our search equilibrium framework this hypothesis can be also formally tested. Bootstrap confidence intervals for the expected durations indicate that the significant departure from the old mean starts already for those, whose income belongs to the third decile of earnings distribution. Thus, recently nearly $65 \%$ of the population revised its expectations about the optimal job duration. The model suggests that such decline is due to the belief that higher wage offer becomes more possible and increased search intensity will therefore be rewarded. This conclusion is furthermore supported by the fact that in 1994 comparatively to 1988 we register a loss of producers monopsony power in wage setting ${ }^{3}$ (see Figure 4), which also implies a potentially higher wage offer. Observing further the pattern of changes in the expected job durations we may see that expected job duration of the poorest agents did not reduce, but to the contrary increased. This increase is not significant yet, but it may have an interesting interpretation, implying a strengthening of competition among labor suppliers. Those who are less competitive and earn the lowest wages foresee that it will be difficult to get a better job and so prepare to stay longer in their relatively poor conditions. Such a reverse change could also be interpreted as a possible tendency towards state dependence of low-wage earners.

Detected significant increase in job mobility of the workers, who earn average and higher wages brings us to the next point of our analysis. Namely, we ask a question whether this increase have caused any changes in equilibrium profit of the firms. To answer we inspect a profit ratio of a representative firm. Using (3), (4) and some algebra we write this ratio as

$$
\frac{\pi^{*}}{\pi}=\frac{M^{*} / N^{*}}{M / N} \frac{p^{*}-w^{*}}{I_{w}(p-w)}\left[\frac{\kappa_{0}^{*}\left(1+\kappa_{0}\right)}{\kappa_{0}\left(1+\kappa_{0}^{*}\right)} \frac{\left(1+\kappa_{1}^{*}\right)\left(1+\kappa_{1} \bar{F}(w)\right)}{\left(1+\kappa_{1}\right)\left(1+\kappa_{1}^{*} \bar{F}^{*}\left(w^{*}\right)\right)}\right]
$$

\footnotetext{
${ }^{3}$ Index of monopsony power is defined as $(p-w) / p$. See Bontemps et al. (2000) for details.
} 
where $\pi^{*}$ and $\pi$ are the profits at the two different periods of time (asterisk defines values of 1994). The expression in square brackets is entirely dependent on observed wages, estimated parameters and estimated offer distribution. Productivity in the ratio of productivity-wage differences is available from (5). To make productivity-wage differences comparable the denominator is scaled by the index of agreed minimum wages $I_{w}$. Finally $M / N$ represents a total labor force over the number of active firms.

Again, the profit ratio is constructed for the ten representative firms that belong to ten different deciles of the support of productivity distribution. Each firm operates on the average productivity of its own decile. From the plot of this ratio (see Appendix, Figure 5) we see that for all firms starting from the third decile profit decline over time is substantial. This behavior is observed along with the increase of labor mobility of the workers who earn wages of the third decile of earnings distribution, and higher. Therefore the main message is that excessive labor mobility may indeed negatively affect producers. Moreover the ratio demonstrates that for the producers who employ more productive, read skilled, labor the loss is higher. Naturally this relationship should not hold for the low-skilled workers since in this case firms do not invest into the human capital of their employees. This fact is also supported by the results. We register no reduction in profits of low-productivity firms.

Thus search equilibrium supports the conjecture of Url and Mayrhuber (1999) about negative relationship between high labor mobility and profitability. Though, we need to notice that in this framework we can not separate the mobility effect from possible exogenous loss of monopsony power.

\subsection{Estimation Results - The Model with Observed Hetero- geneity}

In this part of the work we do not consider firms and focus on the duration dynamics of heterogeneous workers only. We suggest that workers are different with respect to their age and gender and use the specification from Section 4.3 to reestimate the model. Direct estimation results presented in Table A2 of Appendix are again used to recover the expected durations predicted for heterogeneous groups by the model. These durations are reported in Tables 4 and 5 for 1988 and 1994 years respectively.

Table 4 "Expected Durations of Heterogeneous Agents: 1988 (months)"

\begin{tabular}{|c|c|c|c|c|}
\hline & & $\begin{array}{l}\text { Mean Unempl. } \\
\text { Duration }\end{array}$ & $\begin{array}{l}\text { Mean Empl. } \\
\text { Duration }\end{array}$ & $\begin{array}{c}\text { Mean Waiting Time } \\
\text { until Match Break }\end{array}$ \\
\hline \multirow{3}{*}{ Males } & Age & & & \\
\hline & 30 & $3.016(0.084)$ & $142.022(2.700)$ & $102.934(6.465)$ \\
\hline & 45 & $6.634(0.088)$ & $251.169(5.747)$ & $153.230(6.465)$ \\
\hline
\end{tabular}


Females

\begin{tabular}{cccc}
30 & $5.137(0.134)$ & $575.467(2.556)$ & $146.271(6.466)$ \\
45 & $11.301(0.137)$ & $1006.91=\infty$ & $217.743(6.466)$ \\
& & $(5.583)$ & \\
\hline
\end{tabular}

(standard errors in parenthesis)

To demonstrate the age effect we evaluate expected durations for both man and women at 30 and 45 noticing that overall effect of age on any duration is positive. This conclusion comes from the negative sign of the age coefficient in $1 / \exp ($.$) trans-$ formation. The results for expected employment duration presented in Tables 4-5 are computed for both men and women that earn an average income.

Table 5 "Expected Durations of Heterogeneous Agents: 1994 (months)"

\begin{tabular}{lcccc}
\hline \hline \multirow{6}{*}{ Age } & $\begin{array}{c}\text { Mean Unempl. } \\
\text { Duration }\end{array}$ & $\begin{array}{c}\text { Mean Empl. } \\
\text { Duration }\end{array}$ & $\begin{array}{c}\text { Mean Waiting Time } \\
\text { Until Match Break }\end{array}$ \\
\cline { 2 - 3 } & & & & \\
& 30 & $4.662(0.066)$ & $157.181(3.470)$ & $77.801(2.744)$ \\
Females & 45 & $13.564(0.080)$ & $285.713(9.632)$ & $150.795(2.744)$ \\
& 30 & $8.304(0.106)$ & $390.218(3.192)$ & $109.526(2.744)$ \\
& 45 & $24.160(0.115)$ & $709.31=\infty$ \\
& & $(9.206)$ & $212.285(2.744)$ \\
\hline \hline
\end{tabular}

(standard errors in parenthesis)

As it may have been expected we see that within each year males are more mobile than females no matter if employed or unemployed. Moreover, the difference in the length of expected employment duration between men and women is increasing with age of both. This implies that with time females become relatively less ambitious in finding a better job comparatively to males. Moreover, it could be interesting to see that difference in the length of expected unemployment duration between men and women does not depend on age. This implies that attitude to unemployment for both genders remains the same all the time.

A striking result is obtained by looking at the dynamics of male-female job mobility. From the previous analysis we remember the overall reduction in the expected employment duration. Now observing males only we can see that in 1994 comparatively to 1988 their mean job duration did not fall at all. At the same time female expected employment duration experienced about 30\% decrease. Thus there were exclusively females who contributed to the above mentioned overall decline. So we may suggest that over the last decade women in the Austrian labor market became 
more competitive. Alternatively, certain entry barriers in climbing up the career ladder might have been reduced. Be it first or second, this finding in any case positively characterizes the market performance.

\subsection{An Attempt of Sensitivity Analysis}

The literature on the estimation aspects of search equilibrium models with continuous productivity dispersion is clearly an emerging one. Insofar it was advised to go through a nonparametric procedure for a computational simplicity reasons. It is also believed that nonparametric approach performs better then any parametric alternative. Though neither of existing papers have ever presented a formal justification of these claims. To check whether it is indeed so we compare the estimated wage offer distributions with their parametric counterparts. In the case of wage offer distribution the most natural candidate could be a Pareto family (see Figures 1-2).

Table 6 "Tests of Goodness of Fit for the Wage Offer Distribution"

\begin{tabular}{|c|c|c|c|c|}
\hline \multirow[t]{2}{*}{ Test } & \multicolumn{2}{|c|}{$\begin{array}{c}\text { Sample 1988: } \\
H_{0}: \quad \alpha=\underline{w}, \beta=3.589\end{array}$} & \multicolumn{2}{|c|}{$\begin{array}{c}\text { Sample } 1994 \\
H_{0}: \quad \alpha=\underline{w}, \beta=3.359\end{array}$} \\
\hline & Test Statistic & p-Value & Test Statistic & p-Value \\
\hline $\begin{array}{l}\text { D-Kolmogorov } \\
\text { Kuiper }\end{array}$ & $\begin{array}{l}0.13360 \\
0.13872\end{array}$ & $\begin{array}{l}0.00000 \\
0.00000\end{array}$ & $\begin{array}{l}0.16298 \\
0.16425\end{array}$ & $\begin{array}{l}0.00000 \\
0.00000\end{array}$ \\
\hline & Test Statistic & $5 \%$ Cr. Value & Test Statistic & $5 \%$ Cr. Value \\
\hline $\begin{array}{l}\text { Cramer- } \\
\text { von Mises }\end{array}$ & 3.68023 & 0.461 & 5.1412 & 0.461 \\
\hline
\end{tabular}

In Table 6 we present the results of testing the wage offer distribution against $\operatorname{Pareto}(\underline{w}, \alpha)$, where scale parameter of Pareto distribution is fixed to the lowest wage paid and shape parameter is the one that minimizes the reported statistics. The decision is based on Kolmogorov D, Kuiper and Cramer-von Mises test statistics. All three tests uniformly reject the hypothesis of the equivalence of assumed and calculated distributions. This leads to a conclusion that estimation results are indeed sensitive to the distributional assumptions on $F(w)$ (alternatively $\Gamma(p)$ ). So we justify that consistent estimation of the parameters of interest may not be insured unless the nonparametric procedure is applied.

\section{Concluding Remarks}

In the present work we use a search equilibrium model with continuous productivity dispersion to describe empirically the dynamics of the Austrian labor market. 
It turns out that the model does well in tracking changes in firms profitability and explanation of their possible reason - excessive labor mobility and changes in market power of the parties. This makes it superior to the empirical duration models, mostly applicable to the description of the labor supply side only. The model is also competitive in explanation of the variations in the mean employment and unemployment durations. Specifically it provides a clear-cut inference on the mean employment durations and their dependence on the offered wages. This advantage allows us to study in details labor mobility of workers and analyze career advancement.

The work discovers that over the last decade competition on the labor supply side of the Austrian labor market became stronger, which increased frictions in unemployed search. It also indicates significant changes in employed search, which was naturally expected given the results on big declines in employment durations available from the empirical literature. Further investigations that take into account observed heterogeneity of workers indicate that these changes happened mostly due to the enhanced activity in the employed female search. This is certainly a positive tendency in the labor market performance. Discovered shifts in labor mobility and relative loss of producers monopsony power explain the subsequent decline in profits, enjoyed by employers due to their more advantageous position on the market previously. Eventually, the model warns about possible state dependence tendency among low-paid workers and outlines the group of those at risk.

Satisfactory overall fit of the model to the collected data suggests that estimated structural parameters can be as well used for calibration of search equilibrium models and subsequent policy simulations. This makes the model especially attractive for the future studies of labor markets.

\section{References}

[1] Bontemps, C., Robin, J.-M. and G. van den Berg, 1999, An Empirical Equilibrium Job Search Model with Search On-The-Job and Heterogeneous Workers and Firms, International Economic Review 40, 1039-1074.

[2] Bontemps, C., Robin, J.-M. and G. van den Berg, 2000, Equilibrium Search with Continuous Productivity Dispersion: Theory and Nonparametric Estimation, International Economic Review 44, 305-358.

[3] Bowlus, A., Kiefer, N. and G. Neumann, 1995, Estimation of Equilibrium Wage Distributions with Heterogeneity, Journal of Applied Econometrics 10, S119S131.

[4] Bowlus, A., Kiefer, N. and G. Neumann, 1995, Equilibrium Search Models and the Transition from School to Work, International Economic Review 42, 317-343.

[5] Burdett, K. and D. Mortensen, 1998, Wage Differentials, Employer Size and Unemployment, International Economic Review 39, 257-273.

[6] Fichtenbaum, R. and H. Shahidi, 1988, Truncation Bias and the Measurement of Income Inequality, Journal of Business and Economic Statistics 6, 335-337. 
[7] Guerre, E., Perrigne, I. and Q. Vuong, 2000, Optimal Nonparametric Estimation of First-Price Auctions, Econometrica 68, 525-574.

[8] Koning, P., Ridder, G. and G. van den Berg, 1995, Structural and Frictional Unemployment in an Equilibrium Search Model with Heterogeneous Agents, Journal of Applied Econometrics 10, S133-S151.

[9] Lancaster, T., 1990, The Econometric Analysis of Transition Data (Cambridge University Press).

[10] Mayrhuber, C. and T. Url, 1999, Short Employment Duration Dominates on the Austrian labor Market, WIFO Monatsberichte 10, 693-703 (in German).

[11] Mortensen, D. and G. Neumann, 1988, Estimating Structural Models of Unemployment and Job Duration, in: Barnett et al., eds., Dynamic Econometric Modelling, (Cambridge University Press) 335-355.

[12] Padgett, W., 1988, Nonparametric Estimation of Density and Hazard Rate Functions when Samples Are Censored, in: Krishnaiah, P., Rao, C., R., eds., Handbook of Statistics, vol. 7, (North Holland, Amsterdam) 313-332.

[13] Ridder, G., 1984, Distribution of Single Spell Duration Data, in: Neumann et al., eds., Studies in labor Market Dynamics, (Springer) 45-71.

[14] Ridder, G. and G. van den Berg, 1998, An Empirical Equilibrium Search Model of the Labor Market, Econometrica 66, 1183-1221.

[15] Winter-Ebmer, R., 1998, Potential Unemployment Benefit Duration and Spell Length: Lessons from a Quasi-Experiment in Austria, Oxford Bulletin of Economics and Statistics 60, 33-45. 


\section{Appendix}

Table A.1 "Estimation Results - Homogeneous Model"

\begin{tabular}{cccccc}
\hline \hline & \multicolumn{2}{c}{ Sample 1988 } & & \multicolumn{2}{c}{ Sample 1994 } \\
\cline { 2 - 3 } \cline { 5 - 6 } & Parameters & Std. Errors & & Parameters & Std. Errors \\
\hline$\beta_{1}$ & -1.69966 & 0.06624 & & -2.50854 & 0.04287 \\
$\beta_{2}$ & -3.50232 & 0.04825 & & -3.59990 & 0.04811 \\
$\beta_{3}$ & -4.87330 & 0.02370 & & -4.78407 & 0.02241 \\
$\log ($ Likelihood $)$ & -37246.69070 & & & -45091.92039 \\
\hline \hline
\end{tabular}

Parameterization: $\lambda_{0}=\exp \left\{\beta_{1}\right\}, \lambda_{1}=\exp \left\{\beta_{2}\right\}, \delta=\exp \left\{\beta_{3}\right\}$.

Table A.2 "Estimation Results - Extension for Observed Heterogeneity"

\begin{tabular}{llrrrrr}
\hline \hline & & \multicolumn{2}{c}{ Sample 1988 } & & \multicolumn{2}{c}{ Sample 1994 } \\
\cline { 3 - 3 } \cline { 5 - 6 } & & Parameters & Std. Errors & & Parameters & Std. Errors \\
\hline \multirow{3}{*}{$\beta_{1}:$} & Constant & -0.05977 & 0.03024 & & 0.01922 & 0.03179 \\
& Age & -0.05256 & 0.00292 & & -0.07120 & 0.00197 \\
& Gender & 0.53272 & 0.12923 & & 0.57728 & 0.09965 \\
& & & & & \\
$\beta_{2}:$ & Constant & -2.83424 & 0.20030 & & -2.66590 & 0.18967 \\
& Age & -0.03801 & 0.00578 & & -0.03984 & 0.00519 \\
& Gender & 1.39920 & 0.11067 & & 0.90931 & 0.10455 \\
& & & & & \\
$\beta_{3}:$ & Constant & -4.18976 & 0.09795 & & -3.37264 & 0.09410 \\
& Age & -0.02652 & 0.00261 & & -0.04412 & 0.00244 \\
& Gender & 0.35138 & 0.05145 & & 0.34201 & 0.05457 \\
$\log ($ Likelihood $)$ & & & & \\
\hline \hline
\end{tabular}

Parameterization: $\lambda_{0}=\exp \left\{\mathbf{x} \beta_{1}\right\}, \lambda_{1}=\exp \left\{\mathbf{x} \beta_{2}\right\}, \delta=\exp \left\{\mathbf{x} \beta_{3}\right\}$. $\mathbf{x}=\{$ Constant, Age, Gender $\}$ 
Graph 1 „Wage Offer and Earnings Densities for Two Samples”
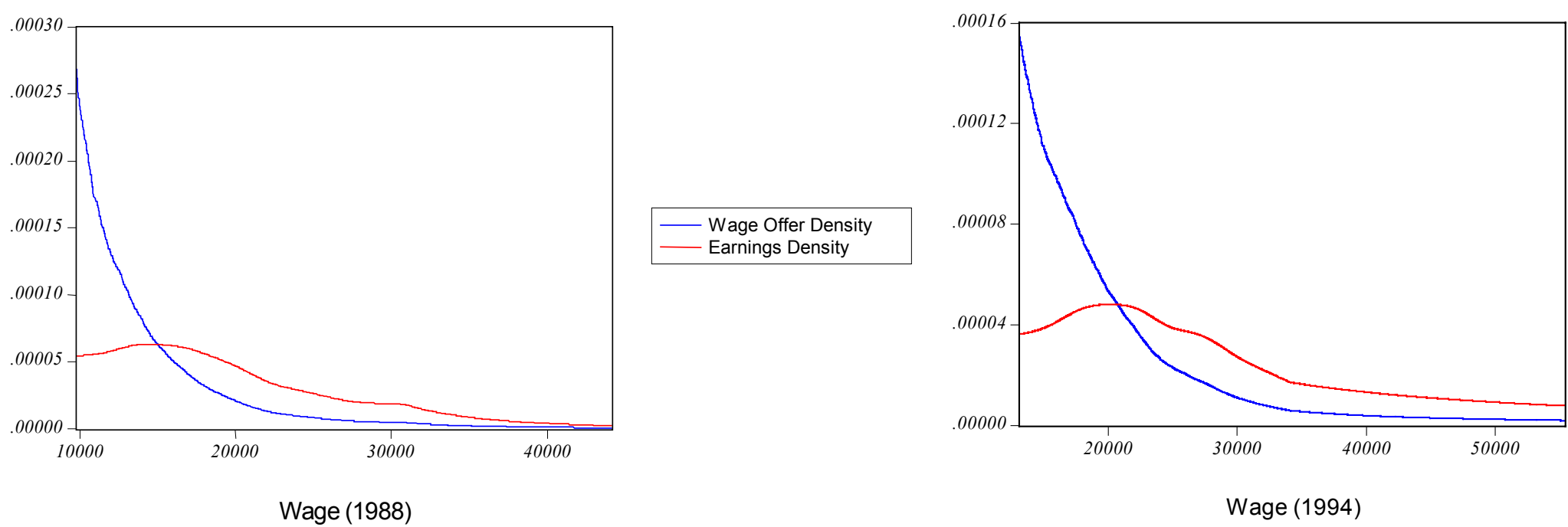

Graph 2 „Wage Offer and Earnings Distributions for Two Samples”
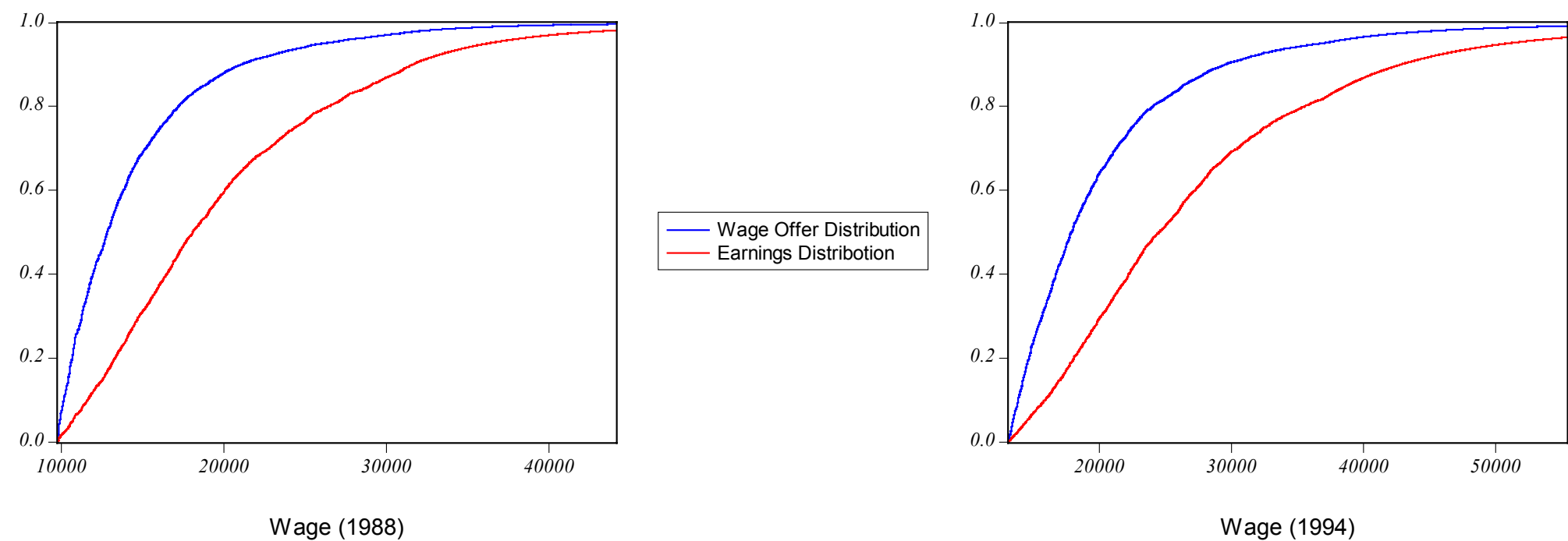

Wage (1994) 
Graph 3 "Expected Job Duration (months)"

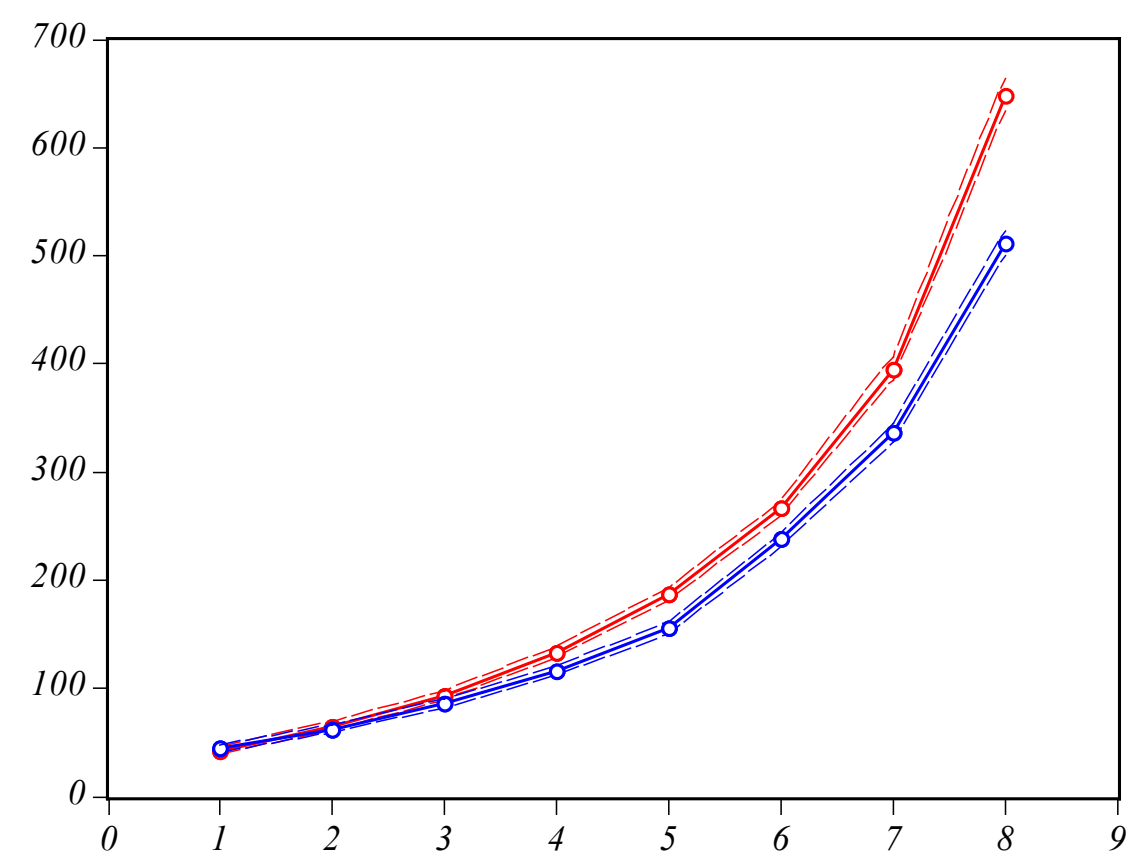

Wage Deciles

--- (confidence bounds for durations in 1988)

- $\ldots$ - Expected Job Duration (1988)

--- (confidence bounds for durations in 1994)

—_ Expected Job Duration (1994) 
Graph 4 "Index of Monopsony Power"
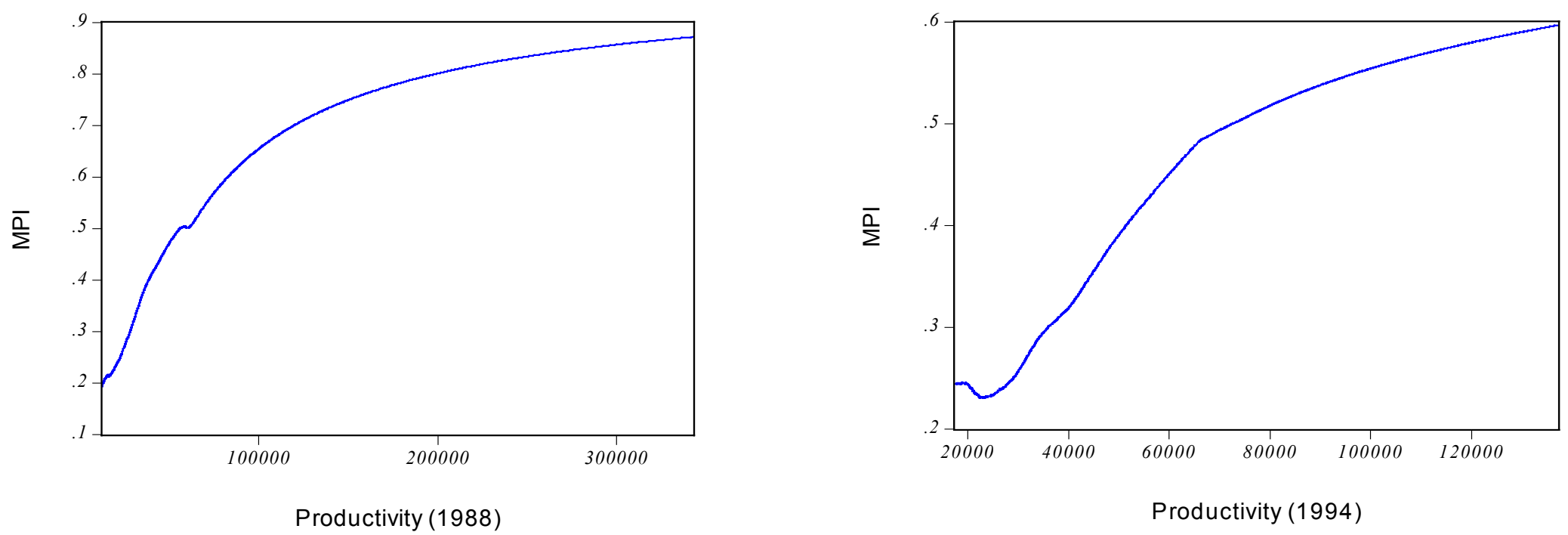

Graph 5 "Profit Ratio Plot"

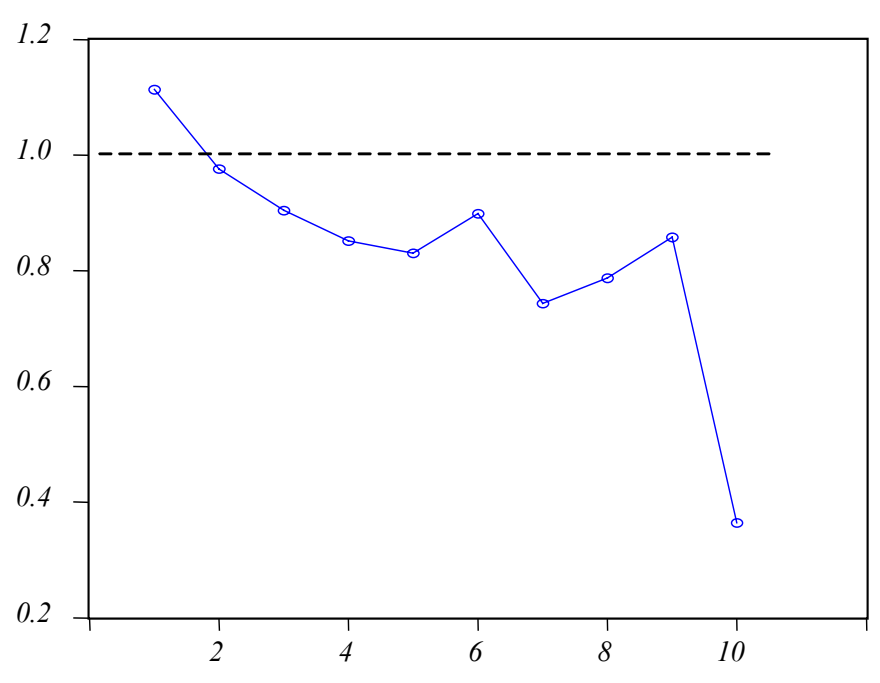

Productivity Deciles 


\section{IZA Discussion Papers}

\begin{tabular}{|c|c|c|c|c|}
\hline No. & Author(s) & Title & Area & Date \\
\hline 787 & $\begin{array}{l}\text { P. Garibaldi } \\
\text { L. Pacelli } \\
\text { A. Borgarello }\end{array}$ & $\begin{array}{l}\text { Employment Protection Legislation and the Size } \\
\text { of Firms }\end{array}$ & 3 & $05 / 03$ \\
\hline 788 & $\begin{array}{l}\text { F. Büchel } \\
\text { J. R. Frick }\end{array}$ & $\begin{array}{l}\text { Immigrants in the UK and in West Germany - } \\
\text { Relative Income Position, Income Portfolio, and } \\
\text { Redistribution Effects }\end{array}$ & 1 & $06 / 03$ \\
\hline 789 & $\begin{array}{l}\text { J. A. Cabral Vieira } \\
\text { A. R. Cardoso } \\
\text { M. Portela }\end{array}$ & $\begin{array}{l}\text { Recruitment and Pay at the Establishment } \\
\text { Level: Gender Segregation and the Wage Gap } \\
\text { in Portugal }\end{array}$ & 5 & $06 / 03$ \\
\hline 790 & $\begin{array}{l}\text { A. Cigno } \\
\text { A. Luporini } \\
\text { A. Pettini }\end{array}$ & $\begin{array}{l}\text { Hidden Information Problems in the Design of } \\
\text { Family Allowances }\end{array}$ & 3 & $06 / 03$ \\
\hline 791 & M. Güell & $\begin{array}{l}\text { Fixed-Term Contracts and the Duration } \\
\text { Distribution of Unemployment }\end{array}$ & 1 & $06 / 03$ \\
\hline 792 & $\begin{array}{l}\text { L. Borghans } \\
\text { B. ter Weel }\end{array}$ & $\begin{array}{l}\text { What Happens When Agent T Gets a } \\
\text { Computer? The Labor Market Impact of Cost } \\
\text { Efficient Computer Adoption }\end{array}$ & 5 & $06 / 03$ \\
\hline 793 & T. Palokangas & $\begin{array}{l}\text { Foreign Direct Investment, Labour Market } \\
\text { Regulation and Self-Interested Governments }\end{array}$ & 3 & $06 / 03$ \\
\hline 794 & $\begin{array}{l}\text { P. Frijters } \\
\text { M. A. Shields } \\
\text { S. Wheatley Price }\end{array}$ & $\begin{array}{l}\text { Investigating the Quitting Decision of Nurses: } \\
\text { Panel Data Evidence from the British National } \\
\text { Health Service }\end{array}$ & 1 & $06 / 03$ \\
\hline 795 & B. T. Hirsch & $\begin{array}{l}\text { Reconsidering Union Wage Effects: Surveying } \\
\text { New Evidence on an Old Topic }\end{array}$ & 3 & $06 / 03$ \\
\hline 796 & P. Apps & Gender, Time Use and Models of the Household & 5 & $06 / 03$ \\
\hline 797 & $\begin{array}{l}\text { E. Bratberg } \\
\varnothing . \text { A. Nilsen } \\
\text { K. Vaage }\end{array}$ & $\begin{array}{l}\text { Assessing Changes in Intergenerational } \\
\text { Earnings Mobility }\end{array}$ & 2 & $06 / 03$ \\
\hline 798 & $\begin{array}{l}\text { J. J. Heckman } \\
\text { J. A. Smith }\end{array}$ & $\begin{array}{l}\text { The Determinants of Participation in a Social } \\
\text { Program: Evidence from a Prototypical Job } \\
\text { Training Program }\end{array}$ & 6 & $06 / 03$ \\
\hline 799 & R. A. Hart & $\begin{array}{l}\text { General Human Capital and Employment } \\
\text { Adjustment in the Great Depression: } \\
\text { Apprentices and Journeymen in UK Engineering }\end{array}$ & 2 & $06 / 03$ \\
\hline 800 & $\begin{array}{l}\text { T. Beissinger } \\
\text { C. Knoppik }\end{array}$ & $\begin{array}{l}\text { Sind Nominallöhne starr? Neuere Evidenz und } \\
\text { wirtschaftspolitische Implikationen }\end{array}$ & 7 & $06 / 03$ \\
\hline 801 & A. Launov & $\begin{array}{l}\text { A Study of the Austrian Labor Market Dynamics } \\
\text { Using a Model of Search Equilibrium }\end{array}$ & 2 & $06 / 03$ \\
\hline
\end{tabular}

An updated list of IZA Discussion Papers is available on the center's homepage www.iza.org. 